\title{
Parametric Study of the Airflow Structure in a Solar Chimney
}

\author{
Badia Ghernaout ${ }^{1}$, Said Bouabdallah ${ }^{1 *}$, Mohammed El Hadi Attia ${ }^{2}$, Müslüm Arıc1 ${ }^{3}, Z_{\text {Zied Driss }}^{4}$ \\ ${ }^{1}$ LME Laboratory of Mechanics, Department of Mechanical Engineering. University of Laghouat, Laghouat 03000, Algeria \\ ${ }^{2}$ LABTHOP Laboratory, Faculty of Sciences, University of El Oued, El Oued 39000, Algeria \\ ${ }^{3}$ Kocaeli University, Engineering Faculty, Mechanical Engineering Department, Kocaeli 41001, Turkey \\ ${ }^{4}$ Laboratory of Electromechanical Systems, National School of Engineers of Sfax, University of Sfax, Sfax 3038, Tunisia
}

Corresponding Author Email: s.bouabdallah@lagh-univ.dz

https://doi.org/10.18280/ijht.380202

Received: 21 March 2020

Accepted: 5 June 2020

\section{Keywords:}

convection, solar chimney, geometrical parameters, solar tower, solar collector

\begin{abstract}
Solar chimney converts solar thermal energy into kinetic energy to generate electricity and it is an alternative technology for electricity generation from solar energy. In this work, we are interested in the study of geometrical parameters on convection airflow within a solar chimney. For this, we have considered a two-dimensional prototype model of a solar chimney. The boundary conditions are chosen to be similar to those in reality. The considered mathematical model is a system of partial differential equations formed by the continuity, momentum, and energy equations in conjunction with the standard k- $\varepsilon$ turbulence model. The numerical simulations were performed by a commercial Computational Fluid Dynamics (CFD) code based on the finite volume method. Good agreements of the present results with experimental and numerical data were obtained. The effects of the tower and collector radius/ heights on the aerodynamic structure were studied and examined. The obtained results can be used for the design of new solar chimney systems.
\end{abstract}

\section{INTRODUCTION}

The development of solar energy use will be linked not only to its economic benefits, which will grow gradually as the fossil energy reserves decline, but also to environmental protection considerations. In fact, no pollutant emissions like smoke containing $\mathrm{CO}_{2}$ and $\mathrm{NO}_{\mathrm{x}}$ from power plants, and no radioactive hazard and bulky waste like nuclear power plants will be observed. A review of the literature confirmed that research-based modeling system aims to improve knowledge and optimize its parts. For example, Maia et al. [1] conducted a numerical and analytical study of turbulent and transient airflow through a solar chimney (SC) using the method of finite volume to evaluate the influence of geometric parameters as well as the materials used on Solar Chimney (SC) performance. Larbi et al. [2] investigated the energy performance of a SC plant projected to provide electricity in isolated villages located in the southwestern region of Algeria. Climate conditions in the southern Algerian regions encourage the exploitation of solar energy, such as solar chimneys and for the production of thermal or electric energy for various uses. Zhou et al. [3] studied experimentally the $\mathrm{SC}$ having $10 \mathrm{~m}$ in diameter of collector and a height equal to $8 \mathrm{~m}$ particularly; they measured the temperature distribution in the considered plant. Ming et al. [4] presented a numerical method for simulating a SC coupled with turbine. As a practical example using the Spanish prototype, they confirmed that the power output of this system is just over 50 kilowatts maximum. Thereafter, they presented simulation and a design of a MW-graded solar chimney power plant system using a 5-blade turbine. In this plant, the power output is equal to $10 \mathrm{MW}$ and the turbine efficiency is about
$50 \%$. Chergui et al. [5] developed a numerical simulation to study the natural convection. Performance studies related to the geometrical and operational parameters were performed. Later, Chergui et al. [6] interested in the configuration geometry of the tower-collector junction and its influence on the thermo-hydrodynamic characteristics of the system. For the sake of prediction of the thermo-hydrodynamic behavior of the system, Bernardes et al. [7] used the method of finite volume in generalized coordinates and performed simulations of laminar free convection in a SC. The mathematical model consisting of momentum and energy balance equations was operated using the finite volume method. Independently from the geometric shape of the physical system, the solution was obtained. This methodology permits particular visualization of geometric effects on the speed and temperature fields, which are very important for the geometry definition and optimum operational characteristics of such systems. The authors proposed also a method for the coordinate's system transformation, equations of elliptic differential for mesh generation for a two-dimensional system. The effect of various geometrical parameters such as temperature, time, and solar radiation on collector diameter and a fixed SC height is studied by Patel et al. [8] with the aim of improving the performance of SC. In another study [9], a 3D turbine connected to a diagram with a solar charge and radiation was used, and it was concluded that the angle of incidence, the shape of the blades and even the control of the speed of rotation influence the efficacy of the tower. Amirkhani et al. [10] studied two models for modeling the behavior of the solar chimney. The first model is the adaptive neuro-fuzzy inference system (ANFIS) and the second model is the artificial neural network (ANN) by considering the 
parameters such as temperature, time, and solar radiation. A numerical study for a Solar Tower Power Plant (STPP) system in Manzanares, Spain was carried out by Sangi et al. [11]. They proposed a model of mathematical founded on Navier-Stokes equations to resolve the flow characteristics of the prototype geometry. The numerical results gave a good result compared to the experimental data. Ghalamchi et al. [12] built a SCPP pilot at the University of Tehran in Iran with a $3 \mathrm{~m}$ in collector diameter and a $2 \mathrm{~m}$ in stack height. The authors estimated the distribution of air velocity and temperature in different settings. The results confirmed that the most suitable option is the zero-sensor angle for small stack solar plants. Nasirivatan et al. [13] studied the SCPP absorber and the effect of the wind on the natural convection flow. They concluded that $14.5 \%$ of the amount of heat transfer had increased. Koonsrisuk [14] compared the behavior of the inclined solar chimney CSCPP and SSCPP by application of the second law of thermodynamics. The results confirmed that the SSCPP performance was much better than that of CSCPP in some configurations. A hybrid system "solar chimney tower cooling" generating electricity and dissipate lost heat at the same time was suggested by Zou et al. [15]. Bernardes and Zhou [16] modeled the conditions of a solar chimney, comprising the irregular border. They evaluated the solar radiation performance of unfavorable conditions at the SCPP and suggested a simple improvement to predict the maximum power. The hydrodynamic behavior of the flow in a solar chimney and the effect of the geometrical parameters on the SC were numerically studied by Lebbi et al. [17]. The effect of the chimney radius on the thermal field indirectly throughout the system by using a change in the mean value of the temperature was examined. The results led to the increase in the chimney radius having a significant impact on improving the behavior of the SC. Jemli et al. [18] studied the performance of a STPP which was proposed and examined firstly in the study of the solar towers in Tunisia. For the considered solar tower prototype characterized by a diameter of $8 \mathrm{~m}$ and a height of $2 \mathrm{~m}$, the results confirmed that the electrical energy reaches $0.3 \mathrm{~W} / \mathrm{m}^{2}$ when the temperature reaches $45^{\circ} \mathrm{C}$. Jianlan et al. [19] developed two models to study the system transmission and construe energy conversion. The first model is a comprehensive mechanism and the second model is a streamlined unsteady mechanism of the SCPPs. The improved results confirmed that the energy quality factor has a significant positive correlation with the stack height. For the stack radius, the power quality factor has a strong negative correlation with the solar power captor. In addition, the optimal height of the solar collector has a quadratic function relationship with the stack diameter. Koonsrisuk et al. [20] suggested the construction theory for SCPP geometry and specified the maximum power and the height/radius ratio. Bernardes and Backstrom [21] accomplished numerical calculation to examine the influence of pressure drop and turbine volume flow on the SCPP performances. Bernardes and Zhou [22] estimated the adverse solar radiation conditions on the performance of the SCPP. They mathematically modeled a solar stack with boundary conditions to calculate the maximum power. Bernardes and Weinrebe [23] presented the effect of various environmental conditions of the SCPP. In addition, impact of the structural dimensions on the performance of the SCPP was studied. They estimated the power of the SCPP. Al Touma et al. [24] examined the impact of a hybrid system utilized to surfaces of glazing to reduce radiation asymmetry and cooling load. The experimental results were matched with the developed model to ensure its validity through experiments conducted in the dual climate chamber of solar radiation, humidity, and ambient temperature conditions. A great agreement was obtained between the measured temperature carried out, the expected temperatures and the loads of the wipers with an accuracy difference of about $4.3 \%$. The results confirmed that the system diminutive is about $19.8 \%$, and significantly mitigated the asymmetry of radiation for offices with a $40 \%$ window-to-wall ratio. System performance decreases when it is exposed in humid climates. Ghalamchi et al. [25] installed a pilot consisting chimney of a SCPP characterized by a diameter of $3 \mathrm{~m}$ and a height of $3 \mathrm{~m}$. Two main effective parameters, namely absorbent material and geometric dimensions were evaluated using velocity and thermal data. The obtained data was used to obtain a structural dimensional formulation of the SCPPs. Recently, Nizetic et al. [26] demonstrated that under steady-state operating conditions the CFD analysis can be applied to simulate stable vortex structure. It was shown that since an operating pressure in an order of several $\mathrm{kPa}$ is required for maintaining a stable vortex high velocities are observed in the updraft zone of the SC. That model was further improved by Penga et al. [27].

As we have mentioned, solar power has gained particular importance in the current era due to the cleanest source of energy. Also, Solar chimney involves high investment costs and traditionally one presents low efficiency. For this, we are interested in the present work to analyze the behavior of the airflow i.e. velocity and temperature fields in an open cavity applied to a solar chimney. Particularly, we have studied the influence of geometrical dimensions on the efficiency of solar chimney, such as the tower and the collector radius and heights. The remainder of this paper is organized as follows: Section 2 describes the physical problem. Section 3 provides the mathematical formulation and numerical solution process. Section 4 discusses the numerical soltion process, which have been used for the computation, the grid independence study, and the comparison between our predictions and the experimental data results. Section 5 presents the results and discussion: parameteric study of the airflow structure in the solar cheminy such as, tower's radius and height, collector's radius and height are presented and discussed. Section 6 contains concluding remarks.

\section{PHYSICAL PROBLEM}

The physical system is a solar chimney prototype used for electricity production (Figure 1). It consists of a tower with a height $\mathrm{Ht}=12.5 \mathrm{~m}$ and a radius $\mathrm{Rt}=0.5 \mathrm{~m}$, mounted on a collector with a radius $\mathrm{Rc}=12.3 \mathrm{~m}$, a height at the entrance $\mathrm{Hc}_{2}=0.05 \mathrm{~m}$ and a height $\mathrm{Hc}_{1}=0.5 \mathrm{~m}$ elsewhere. The boundary conditions are imposed to satisfy the air flow conditions through the solar chimney.

We consider some assumptions commonly made in this type of problems, such as: the fluid is Newtonian and incompressible. The large change in the section between the collector and the tower makes it possible to generate strong pressure gradients then high flow velocities which causes the flow regime to be turbulent. Furthmore, the built of the solar chimney has a symmetry axis (in the tower) for this we consider that the flow is axisymmetric. For the fluid, all the thermo-physical properties are constant except the fluid 
density term, where the volume forces vary linearly with temperature. i.e. the Boussinesq approximation is valid.

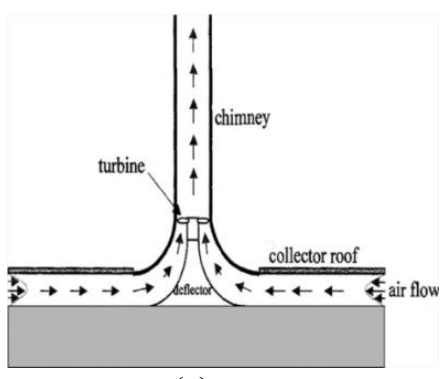

(a)

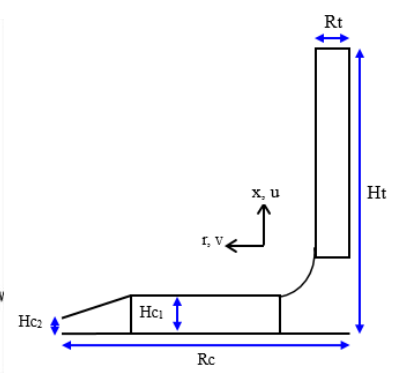

(b)
Figure 1. A sketch of solar chimney (a), and physical model (b) for the present work

\section{MATHEMATICAL FORMULATION}

After the introduction of the assumptions given above, we can consider the average Navier-Stokes equations to describe the phenomenon of natural convection airflow inside the solar chimney.

The continuity equation:

$$
\frac{\partial \rho}{\partial t}+\frac{\partial}{\partial x}(\rho u)+\frac{1}{r} \frac{\partial}{\partial r}(r \rho v)=0
$$

The momentum equation along the $\mathrm{x}$-direction:

$$
\begin{gathered}
\frac{\partial}{\partial t}(\rho u)+\frac{\partial}{\partial x}(\rho u u)+\frac{1}{r} \frac{\partial}{\partial r}(r u \rho v)= \\
-\frac{\partial}{\partial x}\left(p+\frac{2}{3} \rho k\right)+\frac{\partial}{\partial x}\left(\mu_{e} \frac{\partial u}{\partial x}\right)+\frac{1}{r} \frac{\partial}{\partial r}\left(r \mu_{e} \frac{\partial u}{\partial r}\right) \\
+\frac{\partial}{\partial x}\left(\mu_{e} \frac{\partial u}{\partial x}\right)+\frac{1}{r} \frac{\partial}{\partial r}\left(r \mu_{e} \frac{\partial v}{\partial r}\right)+\left(\rho_{0}-\rho\right) g
\end{gathered}
$$

The momentum equation along the r-direction:

$$
\begin{gathered}
\frac{\partial}{\partial t}(\rho v)+\frac{\partial}{\partial x}(\rho v u)+\frac{1}{r} \frac{\partial}{\partial r}(r u \rho v)= \\
-\frac{\partial}{\partial x}\left(p+\frac{2}{3} \rho k\right)+\frac{\partial}{\partial x}\left(\mu_{e} \frac{\partial v}{\partial x}\right)+\frac{1}{r} \frac{\partial}{\partial r}\left(r \mu_{e} \frac{\partial v}{\partial r}\right) \\
+\frac{\partial}{\partial x}\left(\mu_{e} \frac{\partial u}{\partial r}\right)+\frac{1}{r} \frac{\partial}{\partial r}\left(r \mu_{e} \frac{\partial v}{\partial r}\right)-2 \mu_{e} \frac{v}{r^{2}}
\end{gathered}
$$

The energy conservation equation:

$$
\begin{gathered}
\frac{\partial}{\partial t}(\rho T)+\frac{\partial}{\partial x}(\rho u T)+\frac{1}{r} \frac{\partial}{\partial r}(r \rho v T) \\
=\frac{\partial}{\partial x}\left[\left(\frac{\mu}{\operatorname{Pr}}+\frac{\mu_{t}}{\operatorname{Pr}_{t}}\right) \frac{\partial T}{\partial x}\right]+\frac{1}{r} \frac{\partial}{\partial r}\left[r\left(\frac{\mu}{\operatorname{Pr}}+\frac{\mu_{t}}{\operatorname{Pr}_{t}}\right) \frac{\partial T}{\partial r}\right] \\
+\frac{\beta T}{C_{p}}\left[\frac{\partial \rho}{\partial t}+\frac{\partial}{\partial x}(\rho u)+\frac{1}{r} \frac{\partial}{\partial r}(r \rho v)\right] \\
+\frac{\beta T}{C_{p}}\left[-\rho \frac{\partial u}{\partial x}-\rho \frac{\partial u}{\partial x}-\frac{\rho}{r} \frac{g}{\partial r}(r v)\right]
\end{gathered}
$$

In Eqns. (3)-(4) x, r, u, v, p, t, $\rho, r, x, g, \beta, \mu$, Pr and T, are the system coordinate, velocity component, pressure, time, volumetric mass, gravity, thermal coefficient of expansion dynamic viscosity, Prandt number and temperature, respectively.

In this study, the turbulent convection regime was handled by the standard $\mathrm{k}-\varepsilon$ turbulence model, in which, the eddy viscosity $\mu_{t}$ (Eq. (5)) is described in terms of the turbulent kinetic energy (Eq. (6)) and its dissipation rate $\varepsilon$ (Eq. (7)) as follows:

$$
\mu_{t}=\rho C_{\mu} \frac{k^{2}}{\varepsilon}
$$

$$
\begin{gathered}
\frac{\partial}{\partial t}(\rho k)+\frac{\partial}{\partial x}(\rho u k)+\frac{1}{r} \frac{\partial}{\partial r}(r \rho v k)= \\
\frac{\partial}{\partial x}\left(\frac{\mu_{e}}{\sigma_{k}} \frac{\partial k}{\partial x}\right)+\frac{1}{r} \frac{\partial}{\partial r}\left(r \frac{\mu_{e}}{\sigma_{k}} \frac{\partial k}{\partial r}\right)+P_{K}+G_{K}-\rho C_{d \varepsilon} \\
\frac{\partial}{\partial t}(\rho \varepsilon)+\frac{\partial}{\partial x}(\rho u \varepsilon)+\frac{1}{r} \frac{\partial}{\partial r}(r \rho v \varepsilon) \\
=\frac{\partial}{\partial x}\left(\frac{\mu_{e}}{\sigma_{\varepsilon}} \frac{\partial \varepsilon}{\partial x}\right)+\frac{1}{r} \frac{\partial}{\partial r}\left(\frac{\mu_{e}}{\sigma_{\varepsilon}} \frac{\partial \varepsilon}{\partial r}\right) \\
+\left(\frac{C_{1 \varepsilon}}{k}\left(P_{k}+G_{k}\right)\left(1+0.8 R_{F}\right)-C_{2} \rho \frac{\varepsilon^{2}}{k}\right)
\end{gathered}
$$

In these equations, $P_{k}$ stands for the source term of the turbulent kinetic energy and is described as:

$$
P_{k}=\mu_{t}\left[\left(\frac{\partial u}{\partial r}+\frac{\partial v}{\partial x}\right)^{2}+2\left(\frac{\partial v}{\partial r}\right)^{2}+2\left(\frac{v}{r}\right)^{2}\right]
$$

The term $G_{k}$ represents the production of the turbulent kinetic energy produced by the buoyancy force effects. It is given by:

$$
G_{k}=-\frac{\beta g}{\rho} \frac{\mu_{t}}{\operatorname{Pr}_{t}} \frac{\partial T}{\partial x}
$$

The turbulence constants used in the present study are summarized in Table 1.

Table 1. Constants of the standard $k$ - $\varepsilon$ turbulence model

\begin{tabular}{cccccc}
\hline $\boldsymbol{C}_{\boldsymbol{\mu}}$ & $\boldsymbol{C}_{\boldsymbol{D}}$ & $\boldsymbol{C}_{\boldsymbol{I}}$ & $\boldsymbol{C}_{\boldsymbol{2}}$ & $\boldsymbol{\sigma}_{\boldsymbol{k}}$ & $\boldsymbol{\sigma}_{\varepsilon}$ \\
\hline 0.09 & 1 & 1.44 & 1.92 & 1 & 1.3 \\
\hline
\end{tabular}

\section{NUMERICAL SOLUTION PROCESS}

The numerical solution of governing equations associated with the boundary conditions was carried out using the finite volume method. The components of the velocity were stored at staggered locations, and the scalar quantities were stored in the centers of these volumes. The Power Law scheme was considered to evaluate the convection terms at the interface of each control volume. The SIMPLER algorithm (Semi Implicit Method Pressure Linked Equation Revised) for coupling pressure-velocity was applied to solve the velocitypressure coupling. The discretized algebraic equations were 
solved by the line-by-line tri-diagonal matrix algorithm (TDMA) [28-30].

\subsection{Mesh independency test}

In this work, we have considered different grid sizes, namely $11 \times 150,22 \times 250,32 \times 376$ and $42 \times 450$ nodes. Figure 3 shows the velocity and temperature distributions near the ground at $\mathrm{x}=0.025 \mathrm{~m}$ for the different grid sizes. According to these results, the flow parameters values are almost unchangeable when the mesh number is increased to $32 \times 376$ and it is fine enough to obtain accurate results. We chose the grid $32 \times 376$ better than $22 \times 250$, despite being almost coincident for saving the accuracy of the results since comparison with the grid bigger than $42 \times 450$ nodes. This grid is chosen for the all simulations along this work for saving computation time without affecting the accuracy of the results (Figure 2).

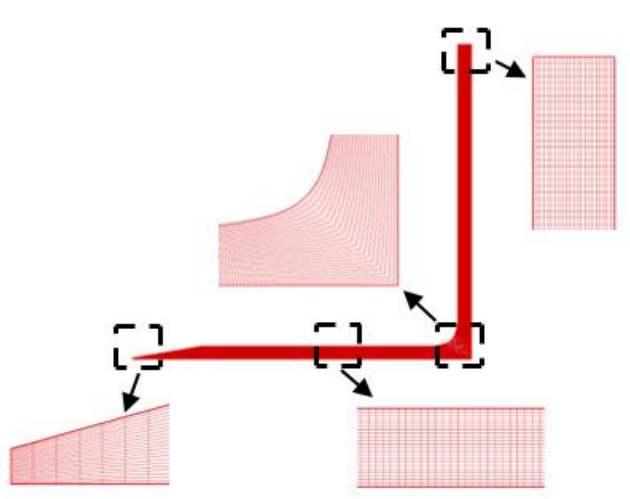

Figure 2. Mesh structure of computational domain

\subsection{Validation and comparison with anterior results}

The obtained numerical results are compared with the experimental and numerical investigations found in the literature. At first, a comparison has been made for the temperature distribution with the experimental results of Maia et al. [1], as illustrated in Figure 4a. From these results, a slight difference between the data has been observed. This behavior can be caused by the boundary conditions imposed on the collector. A further comparison is made with the velocity distribution presented with the numerical results of Lebbi et al. [17], as shown in Figure 4b. From these recent results, the obtained results correspond well with those in ref. [17] corrected by their results.

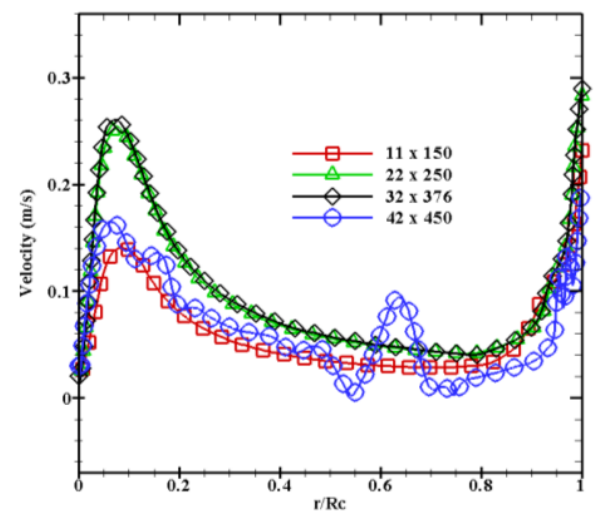

(a)

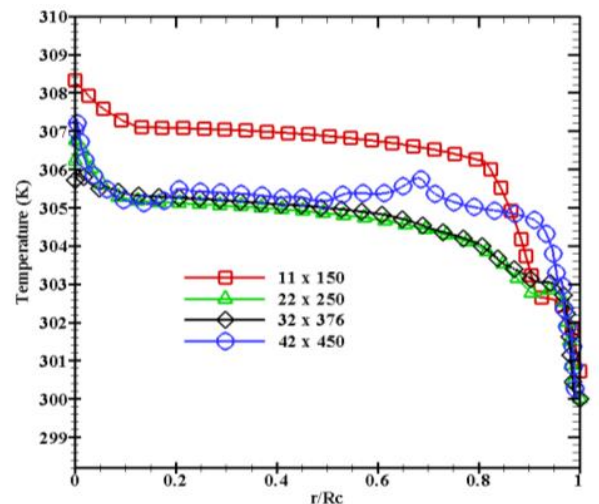

(b)

Figure 3. Comparison of velocity profiles (a) and temperature profiles (b) near the ground (at $\mathrm{x}=0.025 \mathrm{~m}$ ) along the collector radius for various mesh sizes

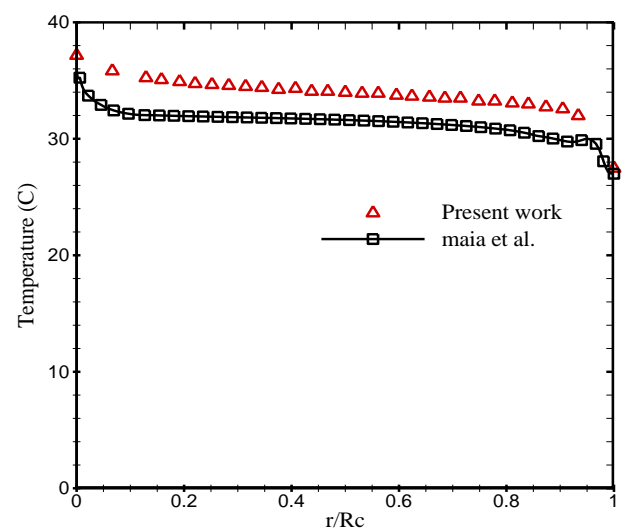

(a)

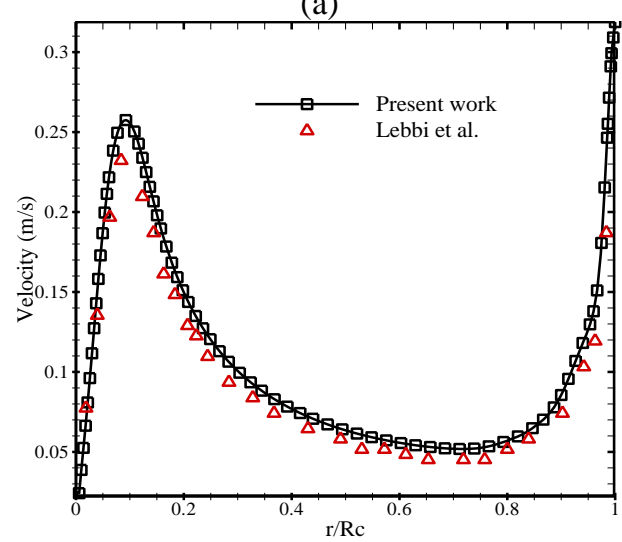

(b)

Figure 4. Variation of temperature and velocity profiles vs. collector radius. Comparison of our results with those of; (a) Maia et al. [1] and (b) Lebbi et al. [17]

\section{RESULTS AND DISCUSSIONS}

It is useful to recall that here we consider a solar chimney prototype used for electricity production. An inlet horizontal velocity at ambient temperature $(300 \mathrm{~K})$ is imposed in the inlet of SC, and it is assumed that boundary conditions of ground velocity are no-slip and imposed temperature is $310 \mathrm{~K}$. On the collector, we imposed also the ambient temperature and so-slip velocity condition, and the conditions of the established flow regime of speed and atmospheric pressure at the chimney outlet. Due to the symmetry condition we take 
only the half of the chimney applying the symmetric conditions at the middle.

\subsection{Effect of the tower's radius (Rt)}

In Figure 5, we have presented the velocity and temperature profiles along the collector radius, for three enlargements of tower radius $\mathrm{Rt}=0.25,0.5$ and $1 \mathrm{~m}$. It is seen from the results presented in the figure that the velocity increases slowly length wise the collector where it takes a maximum value in the interval $\mathrm{r} / \mathrm{Rc}=0.1$ to 0.2 which corresponds to the section of the collector-tower junction. The increase in the radius of the tower is directly proportional to the increase of the velocity along the collector, because increasing the section of the tower will create a pressure drop in it, and then causes the air to easily enter the manifold.

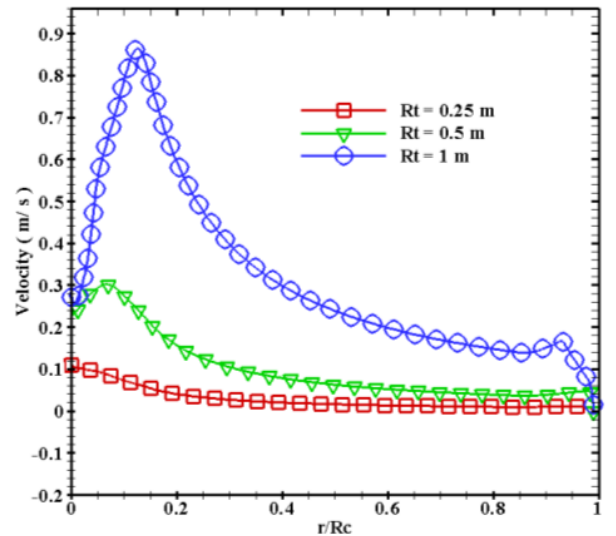

(a)

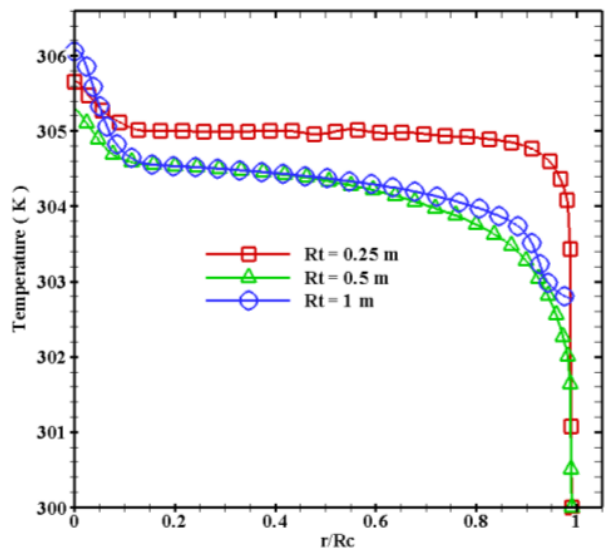

(b)

Figure 5. Profiles of the velocity (a) and temperature (b) near the ground (at $\mathrm{x}=0.25 \mathrm{~m}$ ) along the radius of collector, for different radius of tower

For the temperature, an opposite phenomena has been observed since it declines with as the tower radius increases due to the fact that the increment in the radius of the tower leads to an increase in the overall flow of air that passes through the tower. Therefore, during the same period the air is heated in large quantities in the collector, which reduces the flow temperature in the collector.

\subsection{Effect of the tower's height (Ht)}

In Figure 6 , we have presented the velocity and temperature profiles along the radius of collector, for three tower heights $\mathrm{Ht}=0.25,0.5$ and $1 \mathrm{~m}$. It is evident from these results that an increment in the tower height increases the air velocity inside the collector. Thus, the higher the flow rate generated by the system, the greater the average velocity values from the collector to the tower. For the profiles of the temperature, it is noticed that the increment of the tower height causes a rise in the temperature in the collector due to the pressure increase when increasing the tower height.

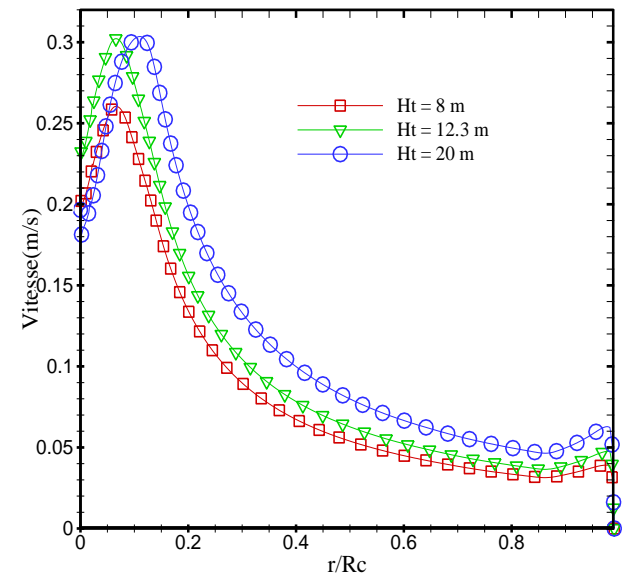

(a)

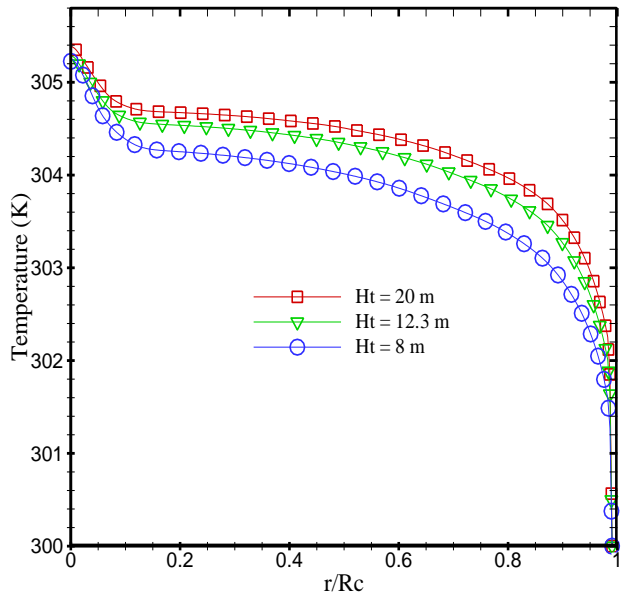

(b)

Figure 6. Profiles of the velocity (a) and the temperature (b) near the ground (at $\mathrm{x}=0.25 \mathrm{~m}$ ) along the radius of collector for different heights of tower

\subsection{Effect of the collector's radius ( $\mathrm{Rc})$}

Figure 7 illustrates the profiles of the velocity and temperature in the collector, for four collector radii, equal to $\mathrm{Rc}=4,8,12.5$, and $20 \mathrm{~m}$. From these results, it has been noted that at the inlet of the collector which corresponds to $r / R c=1$, an increase in cross-flow section has been observed which causes a decrease of the flow rate. This fact is due to the increase in the height of the collector. The temperature changes from the inlet to the outlet of the manifold and increases with increasing radius collector. For collector radius varying from $4 \mathrm{~m}$ to $8 \mathrm{~m}$, the air temperature increases. However, for the large radius values at a certain point, the temperature begins to decrease because of the increase of velocity. The interpretation of the increase in temperature at the intersection by reducing the velocity and the adiabatic boundary conditions. 


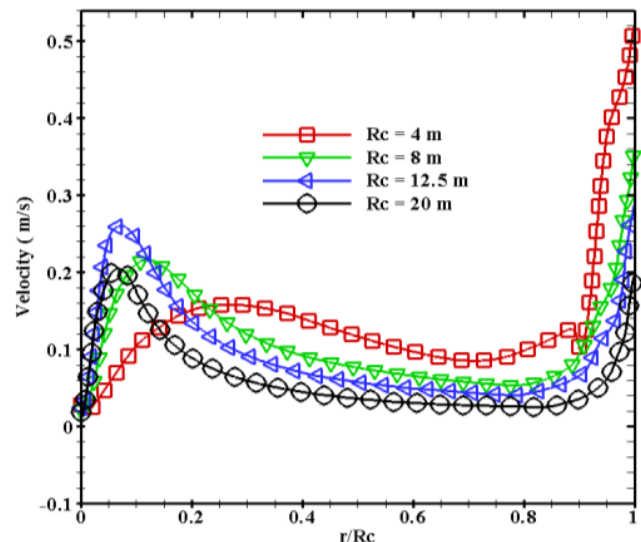

(a)

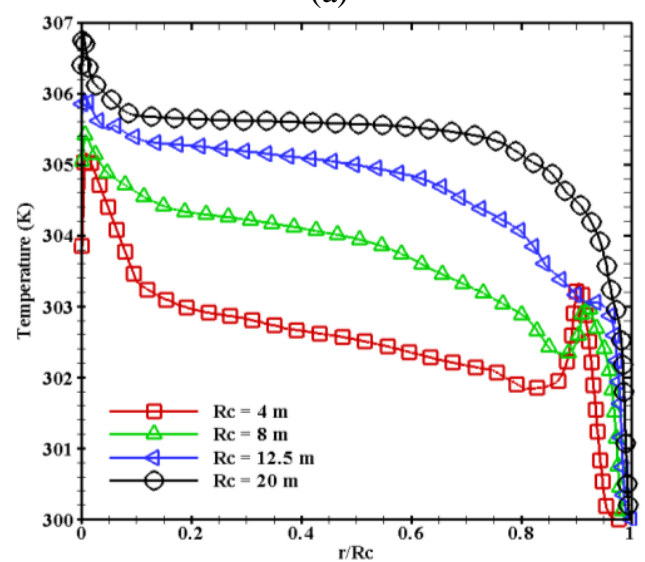

(b)

Figure 7. Variation of velocity profiles (a) and temperature profiles (b) in the vicinity of the ground (at $\mathrm{x}=0.25 \mathrm{~m}$ ) along

the radius of collector for different radius of collector

\subsection{Effect of the collector's height (Hc1)}

Figure 8 shows the air flow streamlines inside the chimney for four collector height values $\mathrm{Hc}_{1}=0.25,0.5,0.75$, and $1 \mathrm{~m}$. From these results, it appears that the airflow velocity is higher for the collector with small heights due to reduced flow area. However, the mass-flow rate augments with the increment of the collector height. For cases of $\mathrm{Hc}_{1}=0.75$ and $\mathrm{Hc}_{1}=1 \mathrm{~m}$ (Figures $8 \mathrm{c}-\mathrm{d}$ ), the presence of the vortices has been observed in the inlet of collector and the junction section, respectively. The vortices in the center increase in size and move upwards occupying almost the entire chimney. This allows the release of a large amount of heat to the outlet.

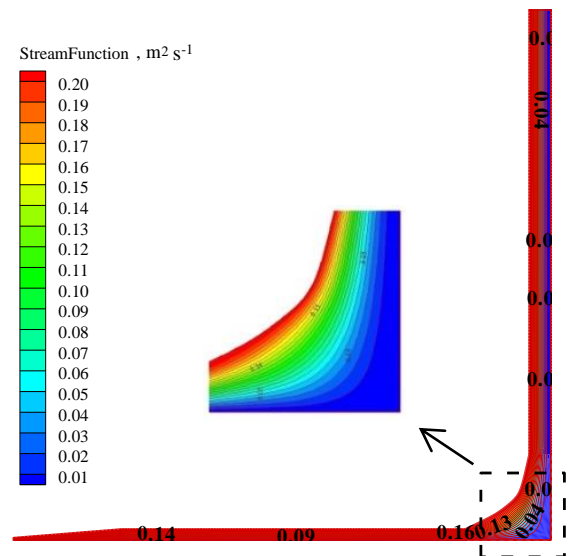

(a) $\mathrm{Hc}_{1}=0.25 \mathrm{~m}$

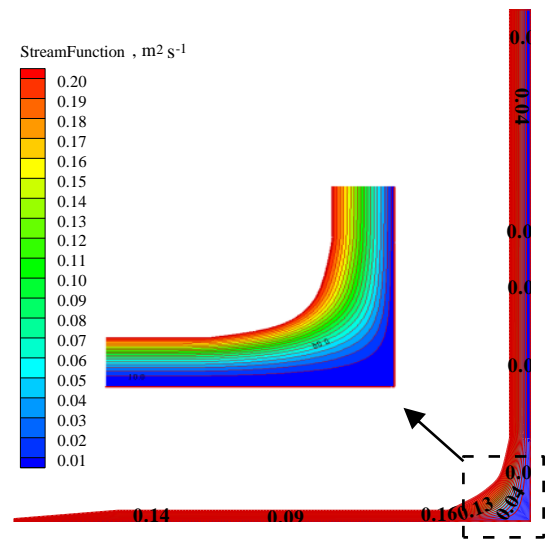

(b) $\mathrm{Hc}_{1}=0.5 \mathrm{~m}$

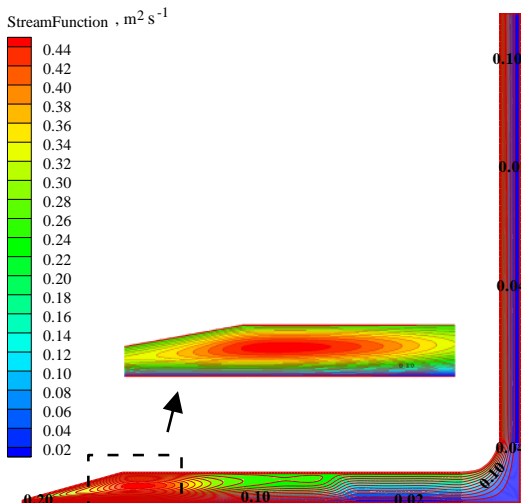

(c) $\mathrm{Hc}_{1}=0.75 \mathrm{~m}$

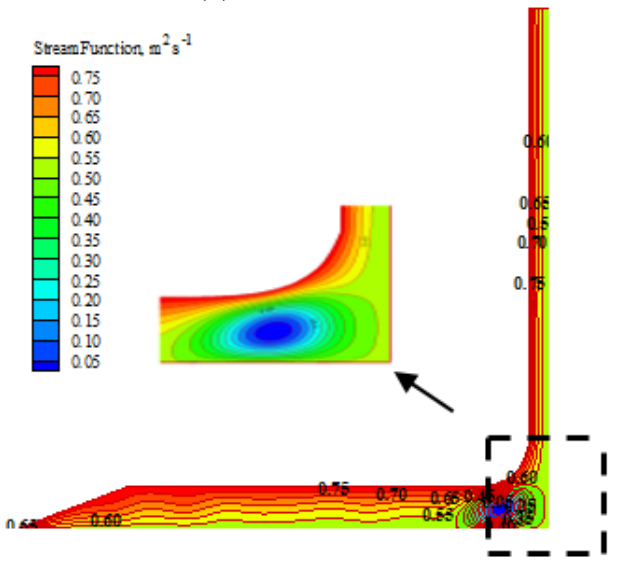

(d) $\mathrm{Hc}_{1}=1 \mathrm{~m}$

Figure 8. Streamlines in the SC plotted for different collector heights

\section{CONCLUSION}

Since the solar chimney involves high investment costs and traditionally one presents low efficiency, we are interested in the present work to analyze the behavior of the airflow. The effect of the design characteristics on the airflow inside a solar chimney was carried out. The obtained simulation results showed a good agreement with the experimental data found in the literature. Numerical methods presents a good way to optimize performance of the present the solar chimney by considering the geometric factors affecting the power generation. The main obtained results can be summarized as follows:

(1). Increasing of the tower's radius expands the mass airflow through the tower, and increases the productivity in 
the junction (turbine).

(2). An increase in the collector height has a direct impact on the air velocity.

(3). An increment in the collector's radius enhances the thermal exchange from the collector inlet to the outlet and intensifies the flow rate at the junction, hence it increases the kinetic energy transferred to the turbine.

(4). The increase of the collector's height reduces the air velocity near the junction, while the temperature increases as a result of raising the airflow rate which presents a large momentum amounts to rotate the turbine.

(5). The gained findings of this study can be helpful for the design and development of the solar chimney systems.

In the future, we propose to develop an experimental model and make it available for other advances.

\section{ACKNOWLEDGMENT}

The authors gratefully acknowledge the Directorate General of Scientific Research and Technological Development (DGSRTD) - to support this work, and fund the LME laboratory for carrying out research.

\section{REFERENCES}

[1] Maia, C.B., Ferreira, A.G., Vall, R.M., Cortez, F.B.M. (2009). Theoretical evaluation of the influence of geometric parameters and materials on the behavior of the airflow in a solar chimney. Computers and Fluids, $38(3)$ : https://doi.org/10.1016/j.compfluid.2008.06.005

[2] Larbi, S., Bouhdjar, A., Chergui, T. (2010). Performance analysis of a solar chimney power plant in the southwestern region of Algeria. Renewable and Sustainable Energy Reviews, 14(1): 470-477. https://doi.org/10.1016/j.rser.2009.07.031

[3] Zhou, X.P., Yang, J.K, Xiao, B., Long, F. (2008). Numerical study of solar chimney thermal power system using turbulence model. Journal of the Energy Institute, $\quad 81(2)$ : 86-91 https://doi.org/10.1179/174602208X303563

[4] Ming, T.Z., Liu, W., Xu, G.L., Xiong, Y.B., Pan, Y. (2008). Numerical simulation of the solar chimney power plant systems coupled with turbine. Renewable Energy, 33(5): 897-905. https://doi.org/10.1016/j.renene.2007.06.021

[5] Chergui, T., Larbi, S., Bouhdjar, A. (2010). Thermohydrodynamic aspect analysis of flows in solar chimney power plants-a case study. Renewable and Sustainable Energy Reviews, 14(5): 1410-1418. https://doi.org/10.1016/j.rser.2010.01.017

[6] Chergui, T., Larbi, S., Bouhdjar, A. (2011). Configuration aspect analysis in solar chimney power plants using finite element method. Procedding of the Eleventh World Renewable Energy Congress, WREC'2011, Linköping, Sweden.

[7] Bernardes, M.A.S., Valle, R.M., Cortez, M.F.B. (1999), Numerical analysis of natural laminar convection in a radial solar heater. International Journal of Thermal Science, 38(1): 42-50. https://doi.org/10.1016/S00353159(99)80015-4

[8] Patel, S.K., Prasad, D., Rafiuddin, A.M. (2014).
Computational studies on the effect of geometric parameters on the performance of a solar chimney power plant. Energy conversion and Management, 77: 424-431.

http://dx.doi.org/10.1016/j.enconman.2013.09.056

[9] Guo, P., Li, J., Wang, Y., Wang, Y. (2015). Numerical study on the performance of a solar chimney power plant. Energy Conversion and Management, 105: 197205. https://doi.org/10.1016/j.enconman.2015.07.072

[10] Amirkhani, S., Nasirivatan, Sh., Kasaeian, A.B., Hajinezhad, A. (2015). ANN and ANFIS models to predict the performance of solar chimney power plants. Renew Energy, 83: 597-607. https://doi.org/10.1016/j.renene.2015.04.072

[11] Roozbeh, S., Majid, A., Behzad, H. (2011). Modeling and numerical simulation of solar chimney power plants. Solar Energy, 85(5): 829-838. https://doi.org/10.1016/j.solener.2011.01.011

[12] Ghalamchi, M., Kasaeian, A., Ghalamchi, M. (2015). Experimental study of geometrical and climate effects on the performance of a small solar chimney. Renewable and Sustainable Energy Reviews, 43: 425431. https://doi.org/10.1016/j.rser.2014.11.068

[13] Nasirivatan, S., Kasaeian, A., Ghalamchi, M., Ghalamchi, M. (2015). Performance optimization of solar chimney power plant using electric/corona wind. Journal of Electrostatics, 78: 22-30. https://doi.org/10.1016/j.elstat.2015.09.007

[14] Koonsrisuk, A. (2013). Comparison of conventional solar chimney power plants and sloped solar chimney power plants using second law analysis. Solar Energy, 98(Part A): 78-84. https://doi.org/10.1016/j.solener.2013.02.037

[15] Zou, Z., He, S. (2015). Modeling and characteristics analysis of hybrid cooling-tower-solar-chimney system. Energy Convers Manage, 95: 59-68. https://doi.org/10.1016/j.enconman.2015.01.085

[16] Bernardes, M.A., Zhou, X. (2013). Strategies for solar updraft tower power plants control subject to adverse solar radiance conditions. Solar Energy, 98: 34-41. https://doi.org/10.1016/j.solener.2013.06.007

[17] Lebbi, M., Chergui, T., Boualit, H., Boutina, I. (2014). Influence of geometric parameters on the hydrodynamics control of solar chimney. International Journal of Hydrogen Energy, 39(27): 15246-15255. https://doi.org/10.1016/j.ijhydene.2014.04.215

[18] Jemli, M.R., Naili, N., Farhat, A., Guizani, A. (2016). Experimental investigation of solar tower with chimney effect installed in CRTEn, Tunisia. International Journal of Hydrogen Energy, 41(13): 1-11. https://doi.org/10.1016/j.ijhydene.2016.07.044

[19] Jianlan, L., Hongjing, G., Shuhong, H. (2016). Power generation quality analysis and geometric optimization for solar chimney power plants. Solar Energy, 139: 228237. https://doi.org/10.1016/j.solener.2016.09.033

[20] Koonsrisuk, A., Lorente, S., Bejan, A. (2010). Constructal solar chimney configuration. International Journal of Heat and Mass Transfer, 53(1-3): 327-333. https://doi.org/10.1016/j.ijheatmasstransfer.2009.09.026

[21] Bernardes, M.A., Von Backstrom, T.W. (2010). Evaluation of operational control strategies applicable to solar chimney power plants. Solar Energy, 84(2): 277-288. https://doi.org/10.1016/j.solener.2009.11.009

[22] Bernardes, M.A., Zhou, X. (2013). On the heat storage 
in Solar Updraft Tower collectors Water bags. Solar Energy, 91: 22-31. https://doi.org/10.1016/j.solener.2012.11.025

[23] Bernardes, M.A., Weinrebe, G. (2003). Thermal and technical analyses of solar chimneys. Solar Energy, 75(6): $511-524$ https://doi.org/10.1016/j.solener.2003.09.012

[24] Al Touma, A., Ghali, K., Ghaddar, N., Ismail, N. (2016). Solar chimney integrated with passive evaporative cooler applied on glazing surfaces. Energy, 115(Part 1): 169-179 https://doi.org/10.1016/j.energy.2016.09.020

[25] Ghalamchi, M., Kasaeian, A., Ghalamchi, M., Mirzahosseini, A.H. (2016). An experimental study on the thermal performance of a solar chimney with different dimensional parameters. Renewable Energy, 91: 477-483. https://doi.org/10.1016/j.renene.2016.01.091

[26] Nizetic, S., Penga, Z., Arıc1, M. (2017). Contribution to the research of an alternative energy concept for carbon free electricity production: Concept of solar power plant with short diffuser. Energy Conversion and Management, 148: 533-553. http://dx.doi.org/10.1016/j.enconman.2017.05.062

[27] Penga, Z., Nizetic, S., Arıc1, M. (2019). Solar plant with short diffuser concept: Further improvement of numerical model by included influence of guide vane topology on shape and stability of gravitational vortex. Journal of Cleaner Production, 212: 353-361. https://doi.org/10.1016/j.jclepro.2018.12.021

[28] Ghernaout, B., Ghernaout, D., Bouabdallah, S. (2017). Two transitions of thermosolutal natural convection in the presence of an external magnetic field. Mathematical Modelling of Engineering Problems, 4(3): 120-125. http://doi.org/10.18280/mmep.040302

[29] Ghernaout, B., Attia, M.E.H., Bouabdallah, S., Driss Z., Benali, M.L. (2020). Heat and fluid flow in an agricultural greenhouse. International Journal of Heat and Technology, 38(1): $\quad 92-98$. https://doi.org/10.18280/ijht.380110

[30] Bouabdallah, S., Bessaïh, R., Ghernaout, B., Benchatti, A. (2011). Effect of an external magnetic field on the 3D oscillatory natural convection of molten gallium during phase change. Numerical Heat Transfer; Part A: Applications, $\quad 60(1)$ : 84-105. https://doi.org/10.1080/10407782.2011.588558

\section{NOMENCLATURE}

$g \quad$ Acceleration of gravitational, $\mathrm{m} \cdot \mathrm{s}^{-2}$

$k \quad$ Turbulent kinetic energy, $\mathrm{m}^{2} \cdot \mathrm{s}^{-2}$

$p \quad$ Pressure, $\mathrm{Pa}$.

Rc Radius of collector, $\mathrm{m}^{-1}$

$R_{t} \quad$ Radius of tower, $\mathrm{m}$

$H_{t} \quad$ Height of tower, $\mathrm{m}$

$H_{C l} \quad$ Height of collector, $\mathrm{m}$

$H_{C 2} \quad$ Collector inlet height, $\mathrm{m}$

$T_{\text {col }} \quad$ Collector temperature, $\mathrm{m}$

$T_{0} \quad$ Ambient temperature, $\mathrm{m}$

$u, v \quad$ Components of velocity, $\mathrm{m} / \mathrm{s}$

$r, x \quad$ Coordinate system, $\mathrm{m}$

\section{Greek symbols}

$\alpha \quad$ Under relaxation factor

$\rho \quad$ Density kg. $\mathrm{m}^{-3}$

$\lambda \quad$ Thermal conductivity, $\mathrm{W} \cdot \mathrm{m}^{-1} \cdot \mathrm{K}^{-1}$

$\mu \quad$ Dynamic Viscosity, $\mathrm{kg} \cdot \mathrm{m}^{-1} \cdot \mathrm{s}^{-1}$

$\varepsilon \quad$ Dissipation rate of the turbulent kinetic energy, $\mathrm{m}^{2} . \mathrm{s}^{-3}$

$\varphi \quad$ Diffusive flux density, W. $\mathrm{m}^{-2}$

$\Phi \quad$ Specific Intensity, W. $\mathrm{m}^{-2}$ 